\title{
Cornelia De Lange Syndrome
}

National Cancer Institute

\section{Source}

National Cancer Institute. Cornelia De Lange Syndrome. NCI Thesaurus. Code C75016.

A rare syndrome characterized by low birth weight, delayed growth, mental retardation, behavioral problems, and a distinctive facial appearance (thin, arched eyebrows, low set ears, small teeth, and small nose). The majority of cases are caused by mutations in the NIPBL gene. Less severe forms of the syndrome are caused by mutations in the SMC1A and SMC3 genes. 